\title{
PARALIMPÍADAS E MÍDIA: O CRESCIMENTO DAS POLÍTICAS DE INCLUSÃO
}


PARALIMPÍADAS E MÍDIA: O CRESCIMENTO DAS POLÍTICAS DE INCLUSÃO

Resumo: Este trabalho busca dialogar sobre o crescente desenvolvimento das políticas de inclusão que agem como estratégias de governamento da população, subjetivando os sujeitos que estão implicados nessas relações. A discussão é feita a partir de um olhar sobre a cobertura realizada pela mídia nas Paralimpíadas dos anos de 2008 e de 2012, o qual mostra uma maior dedicação dos meios de comunicação para esse evento. As ferramentas teórico-metodológicas de análise fazem parte do rol dos Estudos Culturais em Educação.

Palavras chave: Políticas de inclusão; mídia; subjetivação; pessoas com deficiência

\section{JUEGOS PARALÍMPICOS Y LOS MEDIOS: CRECIMIENTO DE LAS POLÍTICAS DE INCLUSIÓN}

Resumen: En este trabajo se busca dialogar sobre el creciente desarrollo de las políticas inclusivas que actúan como estrategias gubernamentales de la población, subjetivando los sujetos que están involucrados en estas relaciones. La discusión se hace por medio de la cobertura realizada por la media en la Paralimpíadas en los años de 2008 e 2012, que muestran una mayor dedicación por parte de los medios para este evento. Las herramientas teóricas y metodológicas de análisis están inclusas en la lista de los Estudios Culturales en la Education.

Palabras clave: Politicas de inclusión; medios; subjetividad; personas con deficiencia

PARALYMPIC AND MEDIA: THE GROWING OF INCLUSION POLICIES

Abstract: This work seeks to dialogue about the increasing development of inclusion policies that act as government strategies for the population, subjecting the subjects who are implicated in these relationships. The discussion is made from a look of media coverage under Paralympics game in 2008 and 2012, which shows a wider dedication of the media for this event. The theoretical-methodological tolls of analysis are part of the Education and Cultural Studies list.

Keywords: Inclusion policies; media; subjectivity, people with disabilities 


\section{PARA ABRIR O DIÁLOGO}

As discussões sobre as políticas de inclusão e o lugar das pessoas com deficiência na Contemporaneidade têm crescido exponencialmente. A inclusão está em voga e alicerçada em condições de possibilidade que a legitimam. Cada vez mais, parece que os preceitos que celebram a inclusão das diferenças nas mais diversas áreas são um caminho unidirecional e o mais correto a ser feito. Dentro dessa perspectiva, as pessoas que possuem deficiência estão sendo inclusas em todos os cenários sociais: nas escolas, nos espaços culturais, no mundo do trabalho e também nos esportes.

Todavia, inscrita na vertente pós-estruturalista dos Estudos Culturais, busco tencionar esse discurso dado como único, tentando "pensar de outro modo".

O "pensar de outro modo" se move a partir de uma atitude de suspeita frente a tudo aquilo que é dado e que parece óbvio e natural. O "pensar de outro modo" significa o exercício de (tentar) pensar por fora do que é dado e já foi pensado, não no sentido de ampliar seus limites, mas sim no sentido de não assumir as bases sobre as quais se assenta esse dado que já foi pensado e, dessa maneira, deixar o já pensado para trás (VEIGA-NETO; LOPES, 2010, p.2).

Sob essa ótica ou "tentando o exercício dessa outra forma de olhar", percebo que os discursos, pela contínua vontade de incluir a todos, estão ancorados em outros objetivos e prerrogativas que os constituem desse modo. Para contribuir com o que afirmo, faço uma breve explanação de como as políticas de inclusão vêm se legitimando nos últimos tempos.

A partir das décadas de 1970 e 1980, países da Europa ocidental e norte-americanos passaram a demonstrar uma "sensibilização" às condições de vida e à falta de participação social das pessoas com qualquer forma de deficiência sensorial ou física ou com distúrbios mentais e psíquicos. As associações que defendiam os direitos dessas pessoas passaram a ter cada vez mais visibilidade e "voz". No final da década de 1980 e no início da década de 1990, vários países passaram a integrar em suas leis formas de atender aos direitos e às necessidades das pessoas com algum tipo de deficiência. Em âmbito geral, as duas Declarações que impulsionaram a ascensão das Políticas de Inclusão foram a Declaração Mundial sobre Educação Para Todos, de 1990, e a Declaração de Salamanca sobre Princípios, Política e Práticas na Área das Necessidades Educativas 
Especiais, de 1994. O crescente interesse por colocar todos na mesma rede e na mesma lógica e a iniciativa de sensibilização de alguns países em relação às condições de vida e aos direitos das pessoas com deficiência estão ancorados também em outras situações. Lavergne (2009) traz algumas reflexões sobre isso, expondo que os grandes difusores de todo esse discurso a respeito de "diversidade", "respeito às diferenças", são as grandes agências internacionais, tais como OMS, UNESCO, FMI e Banco Mundial, que operam dentro de uma forma de economia política neoliberal.

Assim, analisando esses preceitos, pode-se dizer que é através da inclusão das pessoas com deficiência nos diversos cenários sociais que esses sujeitos são, também, incluídos na economia política neoliberal. Dentro dessa lógica é que vejo as Paralimpíadas como uma das estratégias dessas políticas de inclusão, que se propõe a trazer as pessoas com deficiência para as normas da governamentalidade neoliberal.

Não obstante é preciso dizer que essas políticas operam sobre os indivíduos como estratégias de governamento em relação à vida e organização da população (VEIGA-NETO; LOPES, 2007). No caso, as Paralimpíadas são parte desse engendramento, pois suas ações agem em direção ao governamento dos corpos dos indivíduos, subjetivando-os de diversos modos (MACHADO, 2010).

Além disso, dentro dessa mesma perspectiva, percebo que essas políticas de inclusão e suas ações para com os indivíduos estão em ascensão. Cada vez mais somos interpelados por esses discursos que nos constituem, nos convocam a agir de determinado modo e nos governam. Há algum tempo, temas como acessibilidade, direito das pessoas com deficiência, escola inclusiva ou reserva de vagas não tinham significado em nossos cotidianos. Porém, com o advento dessas políticas impulsionadas pela economia neoliberal, os ecos desse discurso estão muito mais presentes e notamos sua ampla divulgação pelos mais diversos aparatos midiáticos.

A partir dessas colocações é que posso dizer que o objetivo deste texto é procurar refletir sobre o crescente discurso das políticas de inclusão através do exemplo da divulgação que alguns dos aparatos midiáticos destinaram às Paralimpíadas nos anos de 2008, em Pequim e de 2012, em Londres. 


\section{PARALIMPÍADAS: UM BREVE OLHAR}

Em uma análise histórica, o primeiro registro de esportes que incluíram pessoas com deficiência remonta ao ano de 1918, na Alemanha. Eram competições de tiro e de arco e flecha em que participavam soldados mutilados na Primeira Guerra Mundial. O segundo registro de esportes para deficientes, cronologicamente, ocorreu em 1932 na Inglaterra, onde foi criada uma Associação de Jogadores de Golfe que possuíam um único braço. No entanto, a grande expansão de esportes para pessoas com deficiência ocorreu com base em uma das leis do mercado, a lei da oferta. Com o final da Segunda Guerra Mundial, inúmeros excombatentes de guerra ficaram mutilados ou com lesões na coluna vertebral, tornando-se paraplégicos ou tetraplégicos. A maior parte desses combatentes era tratada no Centro Nacional de Lesionados Medulares, em Stoke Mandeville, na Inglaterra. Nesse centro, o neurocirurgião alemão Ludwig Gutmann iniciou um tratamento com seus pacientes que incluía o esporte como uma alternativa de reabilitação. Posteriormente, no ano de 1948, aconteceu em Stoke Mandeville a primeira competição para atletas com deficiência, a qual coincidiu com as Olimpíadas, que estavam ocorrendo em Londres. Quatro anos depois, os jogos para atletas com deficiência aconteceram novamente na cidade de Stoke Mandeville na época das Olimpíadas. Já a partir do ano de 1960, os jogos para pessoas com deficiência passaram a acontecer na mesma cidade das Olimpíadas, porém sempre após os Jogos Olímpicos já terem ocorrido.

Os esportes praticados por atletas com algum tipo de deficiência são diferentes dos esportes comumente divulgados e apresentados pela mídia ou conhecidos socialmente. Esses esportes foram criados, adaptados e legitimados pelo Comitê Paralímpico Internacional, que designou cada um deles para um "tipo" de atleta diferente, "encaixando" os participantes de acordo com suas possibilidades ou limitações de movimento. Para exemplificar e esclarecer o que estou afirmando, trago o nome de algumas das competições paralímpicas existentes hoje e para quem são destinadas. Trata-se das seguintes modalidades: o Atletismo (praticado em diversas modalidades e por pessoas com diversos tipos de deficiência), o Basquetebol em Cadeira de Rodas (praticado apenas por cadeirantes), a Bocha (praticada por paralisados cerebrais severos que utilizam

1 De acordo com o Comitê Paraolímpico Brasileiro. Disponível em www.cpb.org.br. Acesso em 14 de setembro de 2012. 
cadeiras de rodas), o Ciclismo (praticado por paralisados cerebrais, deficientes visuais, amputados e lesionados medulares), a Esgrima (praticada por pessoas com deficiência locomotora), o Futebol de Sete (praticado por atletas com deficiência mental), o Futebol de Cinco (praticado por deficientes visuais), o Goalball (praticado por deficientes visuais) o Halterofilismo (praticado por lesionados na coluna vertebral), o Hipismo (praticado por cadeirantes e atletas com deficiência visual), o Judô (praticado por deficientes visuais), a Natação (praticada por deficientes físicos e visuais), o Remo (praticado por deficientes físicos), o Rúgbi em Cadeiras de Rodas e o Tênis em Cadeiras de Rodas (ambos praticados por cadeirantes), o Tênis de Mesa (praticado por amputados de membro inferior com uso de próteses), o Tiro com Arco (praticado por tetraplégicos e paraplégicos), a Vela (praticada por pessoas com deficiência locomotora ou visual) e o Voleibol Sentado (praticado por paraplégicos) (MACHADO, 2010).

Com o advento da inclusão, essa competição cresceu, aumentando o número de participantes a cada ano. Na sua primeira edição, em 1960, havia cerca de 140 participantes. Em Pequim, no ano de 2008, esse número chegou aos 4000 atletas e em Londres, neste ano de 2012, o número de participantes ultrapassou os 4200 atletas - de acordo com o Comitê Paralímpico Internacional.

\section{MÍDIA E CONTEMPORANEIDADE}

A cultura da mídia almeja grande audiência; por isso, deve ser eco de assuntos e preocupações atuais, sendo extremamente tópica e apresentando dados hieroglíficos da vida social contemporânea (KELLNER, 2001, p.9).

A epígrafe traz uma reflexão sobre o papel da mídia na Contemporaneidade. Pode-se dizer que há uma exposição e uma exploração daquilo que eleva os níveis de audiência. Fischer (2001) afirma que "a mídia é um lugar privilegiado de criação, reforço e circulação de sentidos, que opera na formação de identidades individuais e sociais, bem como na produção social de inclusões, exclusões e diferenças" (ibidem, p.588). Nesse sentido, pode-se pensar que a mídia regula o que deve ser dito e o que deve ser pensado, ou seja, regula os discursos.

Sabemos, de acordo com trabalhos como os de Rosa Bueno Fischer, Douglas Kellner, Marisa Vorraber Costa e outros, que a mídia opera como uma produtora e reprodutora dos discursos e saberes, estabelecendo os regimes de 
verdade, regulando o que deve ser dito e legitimando certas representações. "As sociedades e culturas em que vivemos são dirigidas por poderosas ordens discursivas que regem o que deve ser dito e o que deve ser calado e os próprios sujeitos não estão isentos desse efeito" (COSTA, 2000, p.32).

Somos sujeitos pertencentes a um mundo de linguagem que é constitutiva de nossas subjetividades. Essa linguagem, no entanto, está disseminada em todo o tecido social e nas mais variadas instâncias. Para Michel Foucault (2008c), os discursos nos constituem e não possuem apenas um sentido ou uma verdade. Os discursos fazem parte de uma rede maior que os precedem e os englobam. Eles são parte de uma formação discursiva. "Se um enunciado exclui [...] é porque o regime de verdade do qual faz parte esse enunciado se estabeleceu para atender a determinada vontade de verdade" (VEIGA-NETO, 2007, p. 105). Além disso, "os discursos não estão ancorados ultimamente em nenhum lugar, mas se distribuem difusamente pelo tecido social, de modo a marcar o pensamento de cada época, em cada lugar, e, a partir daí, construir subjetividades" (VEIGA-NETO, 2007, p. 100).

Coloco, a partir disso, que os sujeitos estão intrinsecamente conectados a toda a formação discursiva que os sujeitou a argumentarem de uma ou de outra maneira, reforçando certo regime de verdade, e submetidos inegavelmente a relações de poder. O que busco mostrar, dessa forma, é que as reportagens, as entrevistas, os textos e as imagens veiculadas pela mídia sobre as Paralimpíadas têm uma estreita relação com questões de poder e regimes de verdade.

Nesse sentido, a mídia contemporânea como espaço reduplicador dos discursos, apresenta e divulga os regimes de verdade desta época. Ao mostrar, selecionar e narrar certos conceitos, comportamentos e regras, nada mais está fazendo do que fazer circular uma formação discursiva que possui espaço e condições de possibilidade que a tornam legítima e aceitável.

Acredito, dentro dessa perspectiva, que ao mostrar as políticas de inclusão, o que a mídia está fazendo é justamente divulgar os regimes de verdade desta época, ou seja, mostrar o que está na ordem do discurso. Tenciono afirmar, a partir dessas considerações, que a crescente divulgação das políticas de inclusão pela mídia - dentre elas, as Paralimpíadas - tem uma estreita ligação com os discursos desta época, os quais salientam a inclusão de todos dentro das mais variadas instâncias como uma estratégia de governamento em direção a uma economia política neoliberal. 


\section{SUJEITOS, SUBJETIVIDADES E POLÍTICAS DE INCLUSÃO}

De acordo com Nikolas Rose (2001) há uma diversidade de estratégias e táticas de subjetivação que têm se desenvolvido em diversas práticas, em diferentes momentos, e em relação a diferentes classificações e diferenciações de pessoas. O ser humano é alvo de uma multiplicidade de tipos de trabalho. Por isso, pensando nas subjetividades produzidas pela mídia e por outras instâncias, entendo que sujeitos de diferentes tempos subjetivam-se de diferentes modos.

Para Guattari (1993), a produção das subjetividades não escapa dos equipamentos coletivos de subjetivação, tais como as máquinas informacionais e computacionais. Observa-se uma intensificação dos controles sobre o corpo e sobre os processos de subjetivação. Rose (2001) define a subjetivação como

[...] o nome que se pode dar aos efeitos da composição e da recomposição de forças, práticas e relações que tentam transformar - ou operam para transformar - o ser humano em variadas formas de sujeito, em seres capazes de tomar a si próprios como sujeitos de suas práticas e das práticas de outros sobre eles. (ROSE, 2001, p.143).

Ao entender que os processos de subjetivação ocorrem de diversos modos em relação aos diferentes tempos, estratégias e sujeitos, pode-se dizer que somos subjetivados pelos regimes de verdade e pelos discursos de uma época que circulam, também, através da mídia. Nesse caso, as políticas de inclusão são, na Contemporaneidade, uma dessas verdades que subjetivam a todos.

Como colocado anteriormente, essas políticas são oriundas de uma estratégia de mercado que busca incluir a todos dentro das normas da governamentalidade neoliberal. Para Lopes (2009a), no neoliberalismo, certas normas são instituídas para posicionar os sujeitos numa rede de saberes, bem como para criar ou conservar o interesse de cada um em permanecer nas redes sociais e de mercado. Para a autora, duas grandes regras fazem parte desse jogo do neoliberalismo:

A primeira regra é manter-se sempre em atividade. Não é permitido que ninguém pare ou fique de fora, que ninguém deixe de se integrar nas malhas que dão sustentação aos jogos de mercado e que garantem que todos, ou a maior quantidade de pessoas, sejam beneficiados pelas inúmeras ações de Estado e de mercado. Por sua vez, Estado e mercado estão cada vez mais articulados e dependentes um do outro, na tarefa de educar a população para que ela viva em con- 
dições de sustentabilidade, de empresariamento, de autocontrole, etc. A segunda regra é que todos devem estar incluídos, mas em diferentes níveis de participação, nas relações que se estabelecem entre Estado/população, públicos/comunidades e mercado. Não se admite que alguém perca tudo ou fique sem jogar. Para tanto, as condições principais de participação são três: primeiro, ser educado em direção a entrar no jogo; segundo, permanecer no jogo (permanecer incluído); terceiro, desejar permanecer no jogo (LOPES, 2009a, p.155).

Desse modo, analisando essas premissas, foi que percebi - no desenvolvimento da minha Dissertação de Mestrado, desenvolvida na linha de pesquisa dos Estudos Culturais na Universidade Luterana do Brasil - as Paralimpíadas como inscritas no jogo neoliberal, onde não é permitido que ninguém fique de fora: pessoas com ou sem deficiência podem participar de jogos e competições. Além disso, refleti que as políticas de inclusão operam sobre os indivíduos como estratégias de governamento em relação à população (VEIGA-NETO; LOPES, 2007), incidindo suas ações para o governamento - que pode ser entendido como as diversas formas de governar exercidas por várias instâncias da sociedade, as quais exercem poder sobre os sujeitos (FOUCAULT, 2008a), subjetivando-os (MACHADO, 2010).

\section{EVENTOS PARALÍMPICOS DE 2008 E 2012: CONSIDERAÇÕES}

No processo de expansão das políticas de inclusão, a mídia exerce seu papel como uma das divulgadoras desse discurso. Silva (2010) afirma que os discursos que abordam a inclusão social encontram na mídia televisiva as condições de possibilidade para serem exercidas, ou, de acordo com Kellner (2001): "ajudam a urdir o tecido da vida cotidiana, dominando o tempo de lazer, modelando opiniões políticas e comportamentos sociais, e fornecendo o material com que as pessoas forjam sua identidade" (ibidem, p.9).

Utilizando de forma exemplar as Paralimpíadas como uma das políticas de inclusão que ganham visibilidade e voz nos últimos tempos, discuto nesta parte final do trabalho o crescimento da divulgação desse evento. Através de um olhar sobre as reportagens da Revista Veja, do Jornal Zero Hora e de alguns canais de televisão durante as Paralimpíadas de 2008 e de 2012, dialogo com esses artefatos na tentativa de mostrar as diferenças de cobertura e visibilidade dada pela mídia durante essas duas competições. 
A análise que empreendi constou em olhar para alguns artefatos midiáticos. Verifiquei o número de reportagens presentes nas capas do Jornal Zero Hora na data de abertura e na data de encerramento das Paralimpíadas dos anos de 2008 e de 2012 e as reportagens veiculadas pela Revista Veja nas semanas de abertura e de encerramento dos Jogos Paralímpicos desses anos. Além disso, acompanhei a programação do Canal SPORTV² durante a realização dessas competições. Em 2008 as Paralimpíadas ocorreram no período compreendido entre 06/09/2008 e 17/09/2008 e em 2012 aconteceram entre os dias 29/08/2012 e 09/09/2012.

Nas capas do Jornal Zero Hora, tanto no ano de 2008, quanto no ano de 2012, não aparece nenhuma referência sobre essa competição. Pode-se dizer que este meio de comunicação prefere por em destaque assuntos "mais atrativos" para o grande público do que mostrar esse evento que faz parte do rol das políticas de inclusão. Contudo, acredito ser necessário destacar que não direciono meu olhar para as reportagens internas do Jornal Zero Hora. Faço essa escolha porque sei que no interior do mesmo há um caderno de esportes que, desde algum tempo, faz a cobertura desses Jogos. Assim, meu interesse estava em verificar, pela presença ou não de chamada na capa, se a abertura das Paralimpíadas é relevante para o jornal, isto é, se possui visibilidade.

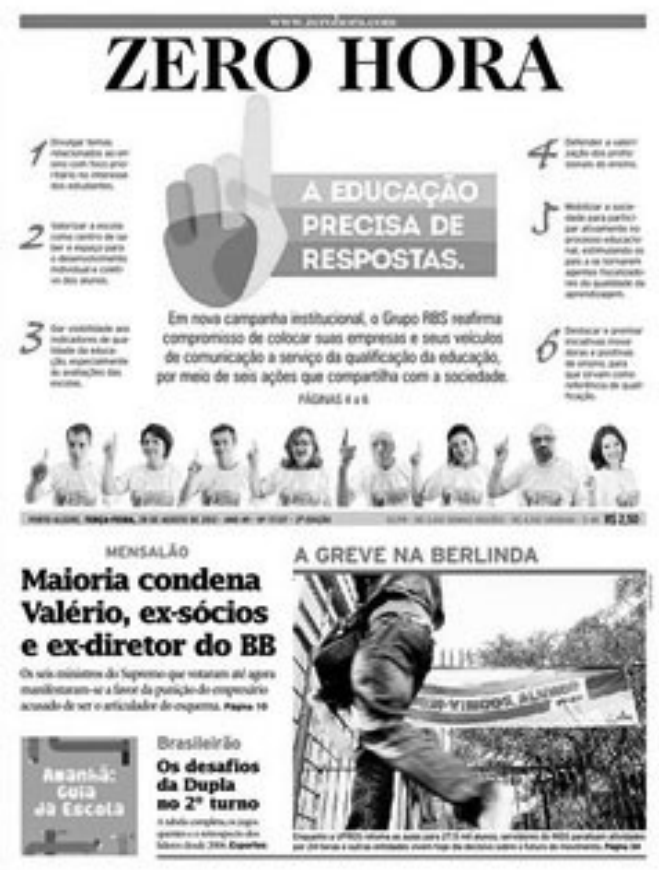

Figura 1: Capa do Jornal Zero Hora de 06.09.2008: Abertura dos Jogos Paralímpicos de Pequim

2 Canal da TV por assinatura que se dedica à programação esportiva. 


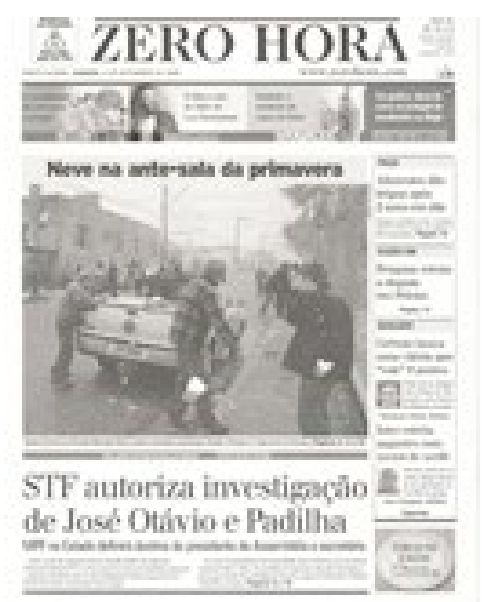

Figura 2: Capa do Jornal Zero Hora de 29/08/2012: Abertura dos Jogos Paralímpicos de Londres

Já na Revista Veja houve uma sutil transformação na cobertura e, de certa maneira, na relevância dispensada para essas competições. No ano de 2008, analisei as edições 2076 de 03/09/2008, a edição 2077 de 10/09/2008 e a edição 2078 de 17/09/2008. No ano de 2012 analisei as edições 2284 de 29/08/2012, a edição 2285 de 05/09/2012 e a edição 2286 de 12/09/2012³.

Ao realizar esse breve olhar sobre a Revista Veja, constato que em nenhum momento das edições do ano de 2008 aparece qualquer citação sobre os Jogos Paralímpicos, seja nas reportagens, nos informes publicitários, nas imagens ou em qualquer outro material veiculado na revista. De outro modo, nas edições de 2012, sempre foi feita alguma referência sobre as Paralimpíadas. Na edição 2284 apareceram informes publicitários da Caixa Econômica Federal e do Banco Bradesco - patrocinadores dos jogos deste ano - anunciando o evento. $\mathrm{Na}$ edição 2285, além da publicidade, foram feitas duas reportagens que narraram a história desses Jogos e discutiram assuntos pertinentes aos mesmos. O olhar sobre a edição 2286 mostra a divulgação dos patrocinadores e uma reportagem sobre o atleta Oscar Pistorius e o uso das tecnologias nas competições.

Assim, noto o avanço que esse artefato passa a dispensar para as Paralimpíadas - entendidas aqui como exemplares das políticas de inclusão - nos últimos quatro anos. Em 2008 na Revista Veja não foi editado nenhum comentário (entrevista, imagem, informe publicitário, etc.) sobre o evento. Esse crescimento pode, então, ser associado ao advento das políticas de inclusão, que cada vez mais tomam seus espaços na sociedade como um todo e, também, 
são divulgadas pela mídia, que põe em circulação os regimes de verdade de um tempo ou de uma época. O que é divulgado através da mídia está submetido à ordem do discurso, articulando o que pode e deve ser dito no jogo de interdições, no momento histórico da produção de sentidos (FOUCAULT, 2008b).

Outro exemplo da expansão das Paralimpíadas na mídia nos últimos anos é a importância que o Canal Sportv destinou a essa competição nos dois anos analisados. No ano de 2008 a cobertura foi feita pela programação habitual do canal, mostrando as competições em que havia brasileiros em destaque participando. Todavia, no ano de 2012, um dos da Sportv dedicou-se, exclusivamente, a mostrar os Jogos Paralímpicos, sejam as competições em que havia brasileiros ou aquelas em que não havia. Isso pode indicar que está acontecendo uma naturalização desse evento no cotidiano contemporâneo. As pessoas, através do crescente investimento nas políticas de inclusão, passam a aceitar, conviver e, de certo modo, valorizar essas ações.

Delineando as últimas colocações deste texto, afirmo que tento imprimir outra forma de olhar para esses processos e, paralelamente, mostrar como é possível suspeitar de verdades que nos são apresentadas como se estivessem sempre aí. Essa análise, porém, é apenas uma maneira de ver essas políticas de inclusão através das Paralimpíadas, problematizando-as, e não de julgar como elas acontecem. Meu interesse foi o de refletir como esses enunciados foram engendrados em nossa sociedade e como passaram a ter significado e constituíram um discurso.

Nessa perspectiva, entendo que as Paralimpíadas - parte das políticas de inclusão - são uma estratégia utilizada para trazer os indivíduos para lógica neoliberal, que pretende atingir a todos, pois há a necessidade de que os sujeitos se percebam com as mesmas condições de atuar e consumir, bem como que tenham desejo de permanecer nesse jogo. "Inclusão na contemporaneidade passou a ser uma das formas que os Estados, em um mundo globalizado, encontraram para manter o controle da informação e da economia" (LOPES, 2009b, p. 129).

Com isso, finalizo refletindo que bem como as políticas de inclusão crescem exponencialmente na Contemporaneidade, também aumenta a visibilidade dada para tudo o que se relaciona com esse discurso inclusivo, que é cada vez mais divulgado pelos diversos artefatos midiáticos. 


\section{REFERÊNCIAS}

COSTA, Marisa Vorraber. Sujeitos e subjetividades nas tramas da linguagem e da cultura. In: CANDAU, Vera Maria (Org.). Cultura, linguagem e subjetividade no ensinar e aprender. Rio de Janeiro: DP\&A, 2000, p. 29-46.

FISCHER, Rosa Bueno. Mídia e educação da mulher: Uma discussão teórica sobre modos de anunciar o feminino na TV. In: Estudos Feministas, 2001, p. 587- 599.

FOUCAULT, Michel. Segurança, território, população. São Paulo: Martins Fontes, 2008a.

. A ordem do discurso. 16.ed. São Paulo: Loyola, 2008b.

. A arqueologia do saber. 7.ed. Rio de Janeiro: Forense Universitária, 2008c.

GUATTARI, Felix. Da produção de subjetividade. In: GUATTARI, Félix. Caosmose: um novo paradigma estético. São Paulo: Editora 34, 1993. p. 11- 44.

KELLNER, Douglas. A cultura da mídia. São Paulo: EDUSC, 2001.

LAVERGNE, Rémi Fernand. A vontade de incluir: Regime de verdade, recomposição das práticas e estratégias de apropriação a partir de um dispositivo de inclusão escolar em Fortaleza. Tese. (Doutorado em Educação). - UFC, Ceará, 2009.

LOPES, Maura Corcini. Políticas de Inclusão e Governamentalidade. Educação \& Realidade, Porto Alegre, v. 34, n. 2, p. 153-170, mai./ago. 2009a.

LOPES, Maura Corcini. Inclusão como prática política de governamentalidade. In: LOPES, Maura Corcini; HATTGE, Morgana Domênica. Inclusão Escolar: conjunto de práticas que governam. Belo Horizonte, Autêntica, 2009b, p. 107- 130.

MACHADO, Roseli Belmonte. Paraolimpíadas e políticas de inclusão: formas de governar os corpos na sociedade e na escola. Dissertação (Mestrado em Educação). Canoas: ULBRA, 2010.

ROSE, Nikolas. Inventando nossos eus. In: SILVA, Tomaz Tadeu da (org. e trad.). Nunca fomos humanos. Belo Horizonte: Autêntica, 2001.

SILVA, Érica Danielle. (In)visibilidade dos corpos deficientes na mídia televisiva: práticas discursivas identitárias em tela. In: $1^{\circ}$ Colóquio Internacional de Estudos Linguísticos e Literários. Anais, 2010.

VEIGA-NETO, Alfredo. Foucault e a educação. 2. ed. Belo Horizonte: Autêntica, 2007. .; LOPES, Maura Corcini. Inclusão e governamentalidade. Educação \& Sociedade, Campinas, v. 28, n. 100, set./dez. 2007, p. 947- 963. .; LOPES, Maura Corcini. Para pensar de outros modos a modernidade pedagógica. ETD - Educação Temática Digital, Campinas, v. 12, n. 1, 2010. p.147-166.

RECEBIDO EM: 15/10/12

ACEITO PARA PUBLICAÇÃO: 06/11/12 


\title{
Roseli Belmonte Machado
}

\begin{abstract}
Mestre em Educação com ênfase nos Estudos Culturais pela Universidade Luterana do Brasil ULBRA/Canoas. Especialista pela Universidade Federal do Rio Grande do Sul - UFRGS e Graduada em Educação Física pela ULBRA/Canoas. Coordenadora Pedagógica em escola da SEDUC/RS. Professora Substituta na ESEF/ UFRGS. Professora de Pós-graduação em Educação Inclusiva.
\end{abstract}

